\title{
O GOVERNO ELETRÔNICO NA GESTÃO DO JUDICIÁRIO'
}

\author{
Aírton José Ruschel'2, Cláudio Eduardo Regis de \\ Figueiredo e Silva ${ }^{3}$, Aires José Rover ${ }^{4}$
}

Resumo: A administração pública no Brasil está sendo repensada, não só em sua atualização tecnológica e na renovação de seus processos administrativos, como também através da participação democrática em sua administração. O Conselho Nacional de Justiça ( $\mathrm{CNJ}$ ) está realizando um grande levantamento sobre o sistema judicial com a edição de metas anuais (2009 e 2010). Um dos objetivos é a efetivação do Processo Eletrônico, através da internet. O Plano Nacional de Banda Larga irá auxiliar a promoção do governo eletrônico, e o judiciário poderá prestar seus serviços, de forma mais qualificada, com os sítios atualmente disponíveis na internet. $O$ real impacto da execução das metas do CNJ e da aplicação do Processo Eletrônico ainda precisa ser mensurado,

1 Este artigo foi apresentado no SID 2010 (Simpósio de Informática e Direito) em Buenos Aires pelo Prof. Aírton José Ruschel, em Agosto de 2010.

2 Professor e Doutorando em Engenharia e Gestão do Conhecimento no Programa de Pós-Graduação (PPGEGC) da Universidade Federal de Santa Catarina (UFSC). E-mail: airtonruschel@gmail.com e http://e-judiciario.blogspot.com

3 Magistrado em Santa Catarina. Diretor de Ensino da Escola Superior da Magistratura do Estado de Santa Catarina (ESMESC). Doutorando no Curso de Pós-Graduação em Direito (CPGD) da Universidade Federal de Santa Catarina (UFSC). E-mail: cerf7996@tjsc.jus.br

4 Professor Doutor do Curso de Pós-Graduação em Direito (CPGD) e do Programa de Pós-Graduação (PPGEGC) em Engenharia e Gestão do Conhecimento da Universidade Federal de Santa Catarina (UFSC). E-mail: aires.rover@gmail.com 
não apenas dentro da estrutura do judiciário, mas da própria concepção de cidadania e de sociedade, que clamam por mais justiça e democracia.

Palavras-chave: Governo Eletrônico. Administração. Democracia. Justiça.

\section{INTRODUÇÃO}

Muitos trabalhos destacam a urgente necessidade de se repensar a Administração Pública no Brasil, mais especificamente o Poder Judiciário, sob a nova realidade em que este se vê ocupando o centro da cena sociológica. Conforme Viana e Burgos, o protagonismo do Judiciário é, assim, menos o resultado desejado por esse Poder do que um efeito inesperado da transição para a democracia, sob a circunstância geral - e não apenas brasileira - de uma restauração das relações entre o Estado e a Sociedade, em consequência das grandes transformações produzidas por mais um surto de modernização do capitalismo. As novas demandas, contudo, chegam a um Judiciário ainda sob forte influência do princípio da separação dos Poderes e de uma adesão ao direito sob a forma de códigos. ${ }^{5}$

Outros países com tradição democrática também têm passado por grandes transformações no Judiciário, principalmente quanto à ampliação e efetivação dos direitos das pessoas, conforme registra Boaventura Santos quando alerta que as demandas do Judiciário têm aumentado nos países democráticos $^{6}$. Nos países democráticos, a busca da Justiça, ou o acesso à Justiça, ocorre por meio do sistema do judiciário e das suas estruturas institucionais montadas pelo governo.

No Brasil, qualquer que seja a orientação político-econômica ou mesmo ideológica, todos reconhecem que a estrutura judicial, cujas raízes ainda estão solidamente fincadas no século

5 Vianna, L.W.; Burgos, M.: Revolução Processual do Direito e Democracia Progressiva, in Vianna, L.W. (Org.): A democracia e os três poderes no Brasil. Belo Horizonte: UFMG, 2002, p. 337/408.

6 Santos, B.S. A sociologia dos tribunais e a democratização da Justiça. In: Pela mão de Alice: o social e o político na pós-modernidade. 2. ed. São Paulo: Cortez, 1996. 
XIX, carece de novos conceitos e novos princípios adequados à dinâmica da sociedade da informação, principalmente pela aplicação das novas Tecnologias da Informação e Comunicação (TIC). É comum ouvir-se que o Judiciário "não estava preparado" para o papel que viria a assumir com a Constituição da República $^{7}$ promulgada em outubro de 1988, que enumera toda uma ordem de direitos individuais, sociais, coletivos e difusos.

Hoje está arraigada no senso comum a concepção de que o sistema judiciário brasileiro é lento e caro, representando um gargalo ao desenvolvimento do País ${ }^{8}$, que demanda instituições jurídicas com credibilidade capazes de proporcionar regras claras e tratamento equitativo aos cidadãos. Para Pimentel, não é possível um país chegar ao desenvolvimento sem que a sociedade resolva prontamente, ou pelo menos num espaço razoável de tempo, os seus conflitos. ${ }^{9}$

São inegáveis os altíssimos índices de congestionamento (relação entre o número de processos pendentes de julgamento no início do ano, o ingresso de novas demandas e o número de decisões proferidas no exercício), o que se traduz em anos e anos à espera de uma sentença e da concretização dessa decisão. Pesquisas de opinião pública confirmam a percepção de que, conforme Dallari, há evidente descompasso entre o Poder Judiciário e as necessidades e exigências da sociedade contemporânea ${ }^{10}$, a ponto de ter sido criado em setembro de 2009, pela Fundação Getúlio Vargas (FGV), o Índice de Confiança no Poder Judiciário ${ }^{11}$.

Aliando-se às percepções da sociedade, a exemplo da pesquisa da FGV, o Judiciário começa a abrir seus registros para

7 Brasil. Constituição da República de 1988. http://www.planalto.gov.br/ccivil_03/ constituicao/constitui\%C3\%A7ao.htm

8 Barral, W. Desenvolvimento e sistema jurídico: a busca de um modelo teórico. In Barral, W.; Pimentel, L.O. (Org.). Teoria Jurídica e Desenvolvimento. Florianópolis: Fundação Boiteux, 2006, p. 11-35.

9 Pimentel, L.O. Direito de propriedade intelectual e desenvolvimento. In: Barral, W. (Org.). Direito e desenvolvimento: um modelo de análise. São Paulo: Singular, 2005.

10 Dallari, D.A. O Poder dos Juízes. $3^{a}$ Ed. São Paulo: Saraiva, 2008.

11 Índice de Confiança no Judiciário da Fundação Getúlio Vargas. http://www.fgv.br/ fgvportal/principal/idx_materia.asp?str_chave=14949\&sessao=2 
a pesquisa acadêmica e também para a pesquisa institucional. Atuam hoje no âmbito do Judiciário, tanto pesquisadores externos ligados às universidades, quanto os operadores da justiça que auxiliam nas informações de pesquisa e gestão solicitadas pela radiografia do Judiciário brasileiro posta em curso pelo Conselho Nacional de Justiça (CNJ).

Em pesquisa em que analisa o fluxo de justiça para o crime de homicídio doloso no Fórum de Florianópolis, descrevendo as fases do fluxo (polícia e justiça), desde o boletim de ocorrência do crime até o desfecho do julgamento e sentença, o antropólogo Aírton José Ruschel aponta para a disparidade do tempo para os diferentes réus e vítimas, gerada tal disparidade principalmente pelos "recursos" dos advogados particulares e públicos, e alerta que o principal sentimento negativo da população se dá em virtude da morosidade dos processos ${ }^{12}$. A pesquisa de Ruschel, que se preocupou com a disparidade do tempo do processo, identifica diferentes tipos sociais que tiveram tratamento diferente em seus processos.

Hygina Bezerra afirma que uma releitura do conceito de acesso à Justiça à luz dos Direitos Humanos nos ensina que esse direito não pode mais ser entendido apenas como a mera possibilidade de propor uma ação em Juízo; pressupõe, também, a manutenção da demanda em trâmite até a prolação da sentença, que deve ser proferida em prazo razoável e efetivada na prática ${ }^{13}$. Pode-se complementar que o processamento deva ser o mais homogêneo que se possa alcançar, independentemente do extrato social a que os envolvidos pertençam. Esse prazo razoável de processamento deve ser cientificamente

12 Ruschel, A.J. Análise do tempo dos Processos Penais de homicídio no Fórum de Justiça de Florianópolis julgados em 2004. Programa de Pós-Graduação em Antropologia Social da Universidade Federal de Santa Catarina. (Dissertação de Mestrado). Florianópolis, 2006. Disponível em http://www.cfh.ufsc.br/ levis/downloads/dissertacao/ATPPHFJFJ2004.pdf Acesso em 09/03/2010.

13 Bezerra, H.J.S.A: Educação para Formação de Juízes-Gestores: Um novo paradigma para um judiciário em crise. p. 1. 2010. Disponível em http://www.cnj.jus.br/ estrategia/wp-content/uploads/2010/03/Higyna-Formação-de-Juízes-Gestores. pdf Acesso em 05/03/2010 
medido, vistos os diferentes tipos analisáveis, e servir para balizar o tempo dos processos penais dentro do contexto da gestão do Judiciário.

Essas ações, que agora estão sendo colocadas em prática, são parte da referida Reforma do Judiciário, que proporcionou o surgimento do CNJ (Conselho Nacional de Justiça) dentro do contexto da reforma administrativa brasileira.

O juiz Cláudio Silva registra que a reforma administrativa foi implantada no Brasil com o Plano Diretor de Reforma do Estado de 1995 e a Emenda Constitucional n. 19, de 04/06/1998, juntamente com inúmeras normas infraconstitucionais que introduziram novos conceitos e princípios como eficiência, controle de resultados, razoabilidade, agências executivas, organizações sociais, privatizações e desregulamentação ${ }^{14}$.

Ao lado da chamada Reforma do Estado, a Reforma do Judiciário iniciada em 2004 completa as grandes reformas do espaço público brasileiro. As reformas política e fiscal nunca aconteceram na prática. Fruto do debate nacional travado em torno da necessidade de controle externo do Poder Judiciário, a Reforma do Judiciário foi implantada pela Emenda Constitucional n. 45, de 8/12/2004, e passou a ser praticada com a instalação do CNJ, previsto no art. 103-B da Constituição, criado em 31 de dezembro de 2004 e instalado em 14 de junho de 2005.

Atendendo ao apelo da sociedade, bem como aos ditames da Reforma do Judiciário, e considerando a disponibilidade das novas tecnologias da informação e comunicação (TICs), o Judiciário brasileiro, capitaneado pelo CNJ está realizando uma radiografia do sistema com a edição de um conjunto de metas anuais (2009 e 2010). O emprego das TICs na prestação de serviço de governo, neste caso do Judiciário, é considerado ação de governo eletrônico.

14 Silva, C.E.R.F: Administração Gerencial e a Reforma Administrativa no Brasil. $1^{\text {a }}$ ed., $7^{\text {a }}$ tiragem. Curitiba: Juruá, 2008. 


\section{O GOVERNO ELETRÔNICO E AS METAS DO CNJ}

O Conselho Nacional de Justiça (CNJ) foi criado no final de 2004, e instalado em junho de 2005, voltado para a reformulação de quadros e meios no Judiciário brasileiro, buscando a transparência administrativa e processual. A transparência e a prestação de contas precisam passar pela melhoria da gestão e, portanto, pela desburocratização.

Rover vê o governo eletrônico como sendo a intercomunicação entre os agentes: o processo de adaptação à via digital passa necessariamente pela desburocratização - um caminho em busca da eficiência e da eficácia frente à capacidade de intercomunicação entre os diversos agentes, superando as diversas barreiras de ordem material, financeira, geográfica ou hierárquica na prestação dos serviços públicos ${ }^{15}$. Como resultado de uma melhor comunicação e de interação entre os operadores do direito, aperfeiçoa-se também sua comunicação com o cidadão e o acesso deste à justiça.

O CNJ coordena as ações de modernização dos 91 Tribunais de Justiça brasileiros e entre suas ações está a aplicação de um conjunto de metas a ser cumpridas por estes Tribunais. Entre outras atividades, foi elencado um conjunto de 10 metas anuais (2009 e 2010) para que sejam atingidas pelos 91 Tribunais.

As ações de governo eletrônico visam a facilitar a acessibilidade ao serviço governamental, possibilitando um maior acesso público à informação e, consequentemente, um governo mais prestador de contas aos cidadãos. A qualificação da gestão com o uso das TICs permite disponibilizar melhores serviços do Judiciário ao cidadão e, com isso, aumentar a possibilidade de acesso à justiça.

Pretende-se neste artigo identificar as ações que beneficiem diretamente o governo eletrônico, tanto na edição 2009, em que o conjunto foi chamado de "metas de nivelamento", quanto

15 Rover, A.J. Introdução ao Governo Eletrônico. In: Rover, A. J. (org). Governo Eletrônico e a Inclusão Digital. Florianópolis: Ed. Boiteux, 2009. p. 22. 
em 2010, em que o conjunto foi tratado como "metas prioritárias". O número sequencial original da meta será mantido entre chaves $\{. .$.$\} conforme o texto do site do CNJ.$

Metas de nivelamento de $2009^{16}$ alinhadas com o e-gov:

- $\{3\}$ Informatizar todas as unidades judiciárias e interligá-las ao respectivo Tribunal e à rede mundial de computadores (internet).

- $\{4\}$ Informatizar e automatizar a distribuição de todos os processos e recursos.

- \{5\} Implantar sistema de gestão eletrônica da execução penal e mecanismo de acompanhamento eletrônico das prisões provisórias.

- \{6\} Capacitar o administrador de cada unidade judiciária em gestão de pessoas e de processos de trabalho, para imediata implantação de métodos de gerenciamento de rotinas.

- \{7\} Tornar acessíveis as informações processuais nos portais da rede mundial de computadores (internet), com andamento atualizado e conteúdo das decisões de todos os processos, respeitado o segredo de justiça.

- \{8\} Cadastrar todos os magistrados como usuários dos sistemas eletrônicos de acesso a informações sobre pessoas e bens e de comunicação de ordens judiciais (Bacenjud, Infojud, Renajud).

- $\{10\}$ Implantar o processo eletrônico em parcela de suas unidades judiciárias.

Em 2009, as metas 3, 4, 5 e 10 tratam da aplicação do governo eletrônico no âmbito interno das instituições do Judiciário, mesmo que esse esforço venha a atingir também o cidadão. As metas 6 e 8 mostram que existe uma ação de inclusão digital internamente nos Tribunais, já que os sistemas estão disponíveis e ainda não são plenamente utilizados em suas funcionalidades pelos operadores da justiça.

Considerando as metas 5 e 6 , é interessante destacar que, atualmente, a implantação de um modelo de gestão passa

16 Metas Prioritárias de 2010 do Conselho Nacional de Justiça. Brasil. www.cnj. jus.br/index.php?option=com_content $\&$ view=article\&id=10350\&Itemid $=1125$ 
necessariamente pelo uso das TICs, em especial pelo software, e também pelo uso do computador integrado à internet. Já a meta 7 , combinada com a 10, mostra um esforço de qualificar a informação e o próprio sistema protocolar do processo (processo digital) e dar ao cidadão, por meio de um portal na internet, a possibilidade de monitorar, sem a necessidade de intermediários, o seu próprio processo.

Metas prioritárias em $2010^{17}$ alinhadas com o e-gov:

- \{5\} Implantar métodos de gerenciamento de rotinas (gestão de processos de trabalho) em pelo menos $50 \%$ das unidades judiciárias de primeiro grau.

- $\{7\}$ Disponibilizar mensalmente a produtividade dos juízes no portal do Tribunal, em especial em quantidade de julgamentos com e sem resolução de mérito e homologatórios de acordos, subdivididos por competência.

- \{8\} Promover cursos de capacitação em administração judiciária, com um mínimo de 40 horas, para 50\% dos magistrados, priorizando-se o ensino à distância.

- \{9\} Ampliar para 2 Mbps a velocidade dos links entre o Tribunal e 100\% das unidades judiciárias na capital e, no mínimo, 20\% das unidades do interior.

- $\{10\}$ Realizar, por meio eletrônico, 90\% das comunicações oficiais entre os órgãos do Poder Judiciário, inclusive cartas precatórias e de ordem.

A meta 5 de 2010, a exemplo dos objetivos de 2009, busca a continuidade da melhoria dos modelos de gestão. A meta 10 de 2010 quer que a comunicação entre os órgãos do Judiciário utilize aquilo que já existe de comunicação informatizada, mas com maior ênfase, através das redes internas ou da internet. A meta 7 é aquela que veio a despertar maior interesse na comunidade do próprio Judiciário, ou seja, o ranking de produção do juiz, algo que requer detalhamento qualitativo dos quantitativos apresentados, pois não basta apresentar os números, é necessário

17 Metas Nacionais de Nivelamento de 2009 do Conselho Nacional de Justiça. Brasil. http://www.cnj.jus.br/index.php? Itemid=963 
contextualizá-los. A meta 8 mostra a sintonia do Judiciário com as possibilidades das TICs, ou seja, além do trabalho do operador da justiça na frente do computador, ele também poderá aprender novidades, através do EaD (Ensino à Distância).

Mas o interessante das metas de 2010 é constatar que aqueles operadores da justiça que efetivamente utilizam a rede para o seu trabalho já não estão mais satisfeitos com a velocidade das transações. A meta 9 busca o aumento da velocidade de comunicação, o que requer investimento em infraestrutura de equipamentos. Essa meta também expõe um problema, que é a desigualdade de acesso à infraestrutura de comunicação do Judiciário, comparando-se as capitais e os mais distantes rincões brasileiros.

As metas anuais e o seu cumprimento são controlados por um sistema informatizado tipo Business Intelligence (BI) que registra e organiza as informações remetidas pelos Tribunais, gerando relatórios analíticos. Os Tribunais ainda passam por dificuldades para organizar a sua informação interna e disponibilizá-la de acordo com o formato daquilo que é pedido pelo conjunto de metas do CNJ.

Conforme os pesquisadores de governo eletrônico no Judiciário Ruschel \& Rover, Business Intelligence é um termo atual, utilizado para referir um conjunto de tecnologias da informação (plataformas, aplicações e processos) cuja finalidade é facilitar a tomada de decisão em todos os níveis de uma organização ${ }^{18}$. $\mathrm{O}$ BI deve ser usado para o controle do conjunto de metas (projetado/realizado) com o uso de indicadores de gestão. Também deve objetivar a análise do tempo dos processos, comparando as variáveis dos tipos internos ao processo com os elementos da infraestrutura, do menor ao maior nível organizacional do Judiciário.

18 Ruschel, A.J.; Rover, A.J. Business Intelligence: Governo Eletrônico na Administração da Justiça. In: Galindo A., F.; Rover, A.J. (eds) Derecho,gobernanza y tecnologías de la información en la sociedad del conocimiento. Prensas Universitarias de Zaragoza. LEFIS Series 7, ISBN 978-84-92774-59-3 pp. 279-298. 2009. p.287. http://zaguan.unizar.es/record/4489/files/ART--2010-002.pdf Acesso em 09/03/2010. 
Alguns Tribunais já trabalhavam com planejamento estratégico há algum tempo. Por exemplo, o Tribunal de Justiça de Santa Catarina, já no ano 2000 começou a aplicar a metodologia de Balance Scorecard (BSC) ${ }^{19}$ desenvolvida pela Harvard Business School. Isso, contudo, ainda é muito pouco, em se considerando o atual estágio da ciência da administração, e tardio, levandose em conta que o movimento mundial de modernização das administrações públicas na busca de maior eficiência (efficiency) e racionalidade nos gastos públicos se iniciou na década de $1980^{20}$. A partir de boas experiências, o CNJ quer difundir o BSC não só para os demais Tribunais, mas também para utilizar na sua própria gestão, na administração do conjunto de metas.

Os 91 Tribunais de Justiça coordenados pelo CNJ que estão participando do processo de qualificação de suas atividades e estruturas são os seguintes:

- 5 Tribunais de 30 Grau (Superiores):

\begin{tabular}{|l|l|l|}
\hline Nome do Tribunal & Sede & Site \\
\hline Supremo Tribunal Federal - STF & Brasília & http://www.stf.jus.br/ \\
\hline Superior Tribunal de Justiça - STJ & Brasília & http://www.stj.jus.br/ \\
\hline Tribunal Superior do Trabalho - TST & Brasília & http://www.tst.jus.br/ \\
\hline Tribunal Superior Eleitoral - TSE & Brasília & http://www.tse.jus.br/ \\
\hline Superior Tribunal Militar - STM & Brasília & http://www.stm.jus.br/ \\
\hline Total: 5 & & \\
\hline
\end{tabular}

Tabela 01 - Tribunais de $3^{\circ}$ grau - Fonte: Os autores

- 86 Tribunais de 2० Grau:

Tribunais de Justiça Estaduais (TJ) - 27

Tribunais Regionais do Trabalho (TRT) - 24

Tribunais Regionais Eleitorais - TRE - 27

Tribunais Regionais Federais (TRF) - 5

Tribunais de Justiça Militar (TJM) - 3

19 Programa estratégico do Tribunal de Justiça de Santa Catarina. http://www.tj.sc. gov.br/institucional/assessorias/asplan/planejamento_estrategico/index.html

20 Silva, C.E.R..F. "Gestão Pública no Poder Judiciário", in Revista da ESMESC/ Escola Superior da Magistratura do Estado de Santa Catarina - v.16, n. 22. Florianópolis: ESMESC, 2009, p. 35/51 
A sede dos Tribunais está sempre localizada nas capitais dos estados de abrangência. Brasília concentra a maioria das sedes, principalmente dos Tribunais superiores. Os sites dos Tribunais na internet foram padronizados com a incorporação do domínio "jus.br" que caracteriza o Judiciário brasileiro.

O mapa georreferenciado da Fig 01 identifica a sede dos 27 Tribunais de Justiça estaduais. $\mathrm{O}$ uso de ferramentas de mapas tornou-se uma tendência forte com a qualificação dos serviços na internet. Isso permite uma análise espacial da disposição de informações em mapas.

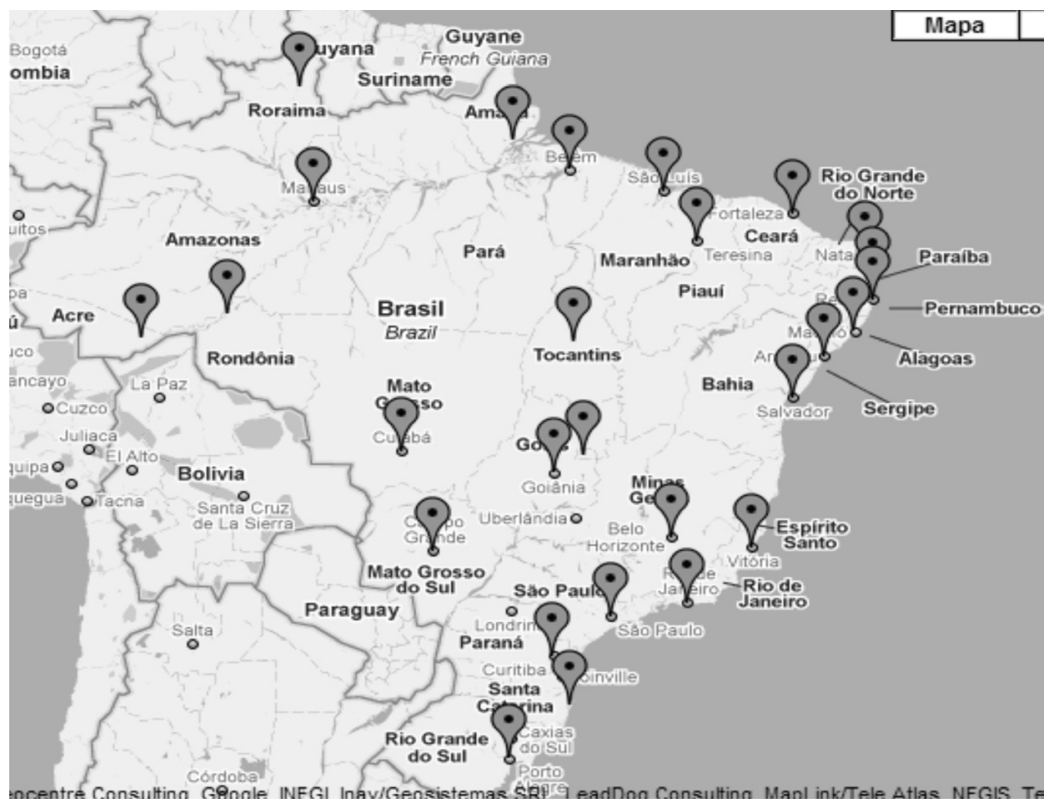

Fig 01 - Localização geográfica da sede dos TJs Fonte: Os autores.

Significativa é a implantação que vem sendo posta em prática pelo Judiciário brasileiro de uma codificação de processo obediente a um padrão único para todos os Tribunais. A padronização do número dos processos no âmbito do Judiciário tem o intuito de facilitar o acesso às informações processuais e de agilizar a prestação jurisdicional. 
As estruturas de composição numérica, que proporcionam maior segurança e celeridade ao jurisdicionado, dispensando memorizações de vários números em processos de uma mesma demanda, possuem vinte dígitos, específicos para identificação de processos, referindo-se:

- à unidade de origem,

- ao ano do ajuizamento do processo,

- ao órgão ou segmento do Poder Judiciário,

- ao Tribunal do respectivo segmento ou circunscrição judiciária.

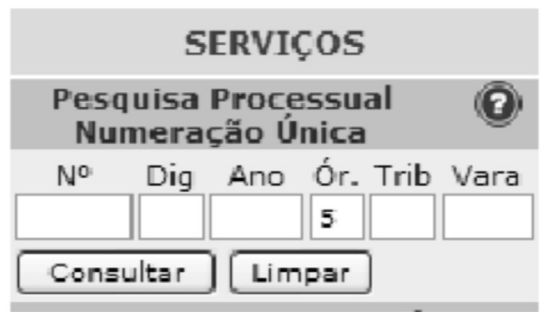

Fig 02 - Pesquisa Unificada do TST21

Como exemplo, no site no TST (órgão n. 5), está disponível uma consulta estruturada que deverá permitir acesso aos processos dos respectivos Tribunais estaduais ${ }^{21}$. Esse modelo de janela de pesquisa vem-se tornando padrão nos sites do Judiciário brasileiro. É uma ação que busca o estabelecimento de portais padronizados para o Judiciário. Na retaguarda, devem estar disponibilizados sistemas informatizados robustos que busquem os processos e seus trâmites nos diferentes bancos de dados, os quais são disponibilizados por diferentes fornecedores de software.

É inegável que, para o atendimento do conjunto de metas do Judiciário, bem como para sanar outras questões gerenciais dos Tribunais, é necessário um grande investimento em TICs, principalmente nos modelos de gestão, os quais passam pelo software e pela comunicação, que hoje depende da internet de banda larga.

21 Tribunal Superior do Trabalho. Brasil. http://www.tst.jus.br/ 
Pode-se afirmar que, já num futuro próximo, para que o Judiciário alcance uma maior capilaridade na sociedade e o cidadão tenha maior acesso à Justiça, são necessários:

- investimentos em internet de banda larga;

- qualificação das interfaces dos sites e portais;

- disponibilização de pontos de acesso, como telecentros, escolas e quiosques;

- efetivação do processo eletrônico; e

- inclusão digital, em questões do Judiciário, para o cidadão.

Os investimentos em infraestrutura de rede banda larga no Brasil ainda são incipientes, mas o governo brasileiro, conhecedor dessa lacuna para que o governo eletrônico (e-gov) se efetive, está lançando o Plano Nacional de Banda Larga (PNBL).

$\mathrm{O}_{\mathrm{PNBL}^{22}}{ }^{22}$ tem o objetivo de fomentar e difundir o uso e o fornecimento de bens e serviços de tecnologias de informação e comunicação (TICs), de modo a:

I - massificar o acesso a serviços de conexão à Internet em banda larga;

II - acelerar o desenvolvimento econômico e social;

III - promover a inclusão digital;

IV - reduzir as desigualdades sociais e regionais;

$\mathrm{V}$ - promover a geração de emprego e renda;

VI - ampliar os serviços de Governo Eletrônico e facilitar aos cidadãos o uso dos serviços do Estado;

VII - promover a capacitação da população para o uso das tecnologias de informação; e

VIII - aumentar a autonomia tecnológica e a competitividade brasileiras.

Analisando as metas do Judiciário, principalmente a implantação e a efetivação do processo eletrônico, aliadas aos objetivos do PNBL, atesta-se a existência de uma sinergia para que os serviços de governo eletrônico, no caso, os serviços do

22 Plano Nacional de Banda Larga. Brasil. http://www.planalto.gov.br/ccivil_03/_ Ato2007-2010/2010/Decreto/D7175.htm 
Judiciário, cheguem mais perto do cidadão. Havendo um maior conhecimento do cidadão quanto aos seus direitos, os quais podem ser pleiteados e mediados pela internet, pode-se afirmar que lhe será proporcionado um maior acesso à justiça, diminuindo a necessidade de intermediários.

Uma questão que ainda precisa ser equacionada, mas que, de alguma forma, as ações de governo eletrônico no Judiciário podem auxiliar, é na resolução de problemas existentes na Justiça de $1^{\circ}$ Grau, ou seja, na instância em que as demandas judiciais do cidadão se iniciam.

Para José Renato Nallini, existe a necessidade de se modernizar a estrutura de primeiro grau e trabalhar a nova administração pública nos cartórios e serventias, introduzindo ferramentas que venham a melhorar a eficiência do sistema. É necessário dotar a Justiça de mecanismos de agilidade, convertê-la em serviço estatal com eficiência comparável à de qualquer atividade reconhecidamente prestigiada pelo êxito de seu funcionamento ${ }^{23}$.

Para que isso aconteça, os juízes precisam buscar constantemente um melhor aproveitamento do aparato criado pelo sistema, convertendo-se em engenheiros sociais e coordenadores de equipes multidisciplinares, os "guardiões de promessas", mencionados por Antoine Garapon quando descreve a emigração do espaço simbólico da democracia do Estado para a Justiçaa ${ }^{24}$. O juiz tem que ser hábil para dar uma "satisfação à sociedade" enquanto equaciona a demanda do cidadão com os recursos materiais e humanos que o sistema judiciário disponibiliza para sua unidade jurisdicional, não podendo se limitar a uma mera atuação burocrática limitada aos recursos disponíveis.

Atualmente, o conjunto de metas do Judiciário, principalmente aquelas que tratam da quantidade de processos a resolver, dá a impressão de que basta o CNJ cobrar para que os Tribunais as repliquem e as unidades de $1^{\circ}$ grau as cumpram, com a consecutiva satisfação da sociedade. É sabido que as estruturas

23 Nallini, J.R. A Rebelião da Toga. Campinas: Millenium, 2006. p. 163

24 Garapon, A. O juiz e a democracia: o guardião de promessas. Trad. Maria Luiza de Carvalho. $2^{\text {a }}$ Ed. Rio de Janeiro: Revan, 2001. p. 45 
do Judiciário não chegam à maioria dos rincões brasileiros, por falta de recursos orçamentários, de pessoal e de estrutura física e até falta de acesso por inexistência de estradas.

A radiografia desenvolvida hoje pelo $\mathrm{CNJ}$ é muito importante, pois mostra um comprometimento da cúpula do Judiciário com o processo de modernização. Mas é necessário que o diálogo prometido entre o Judiciário e o cidadão se dê também nas hierarquias internas do Judiciário, promovendo assim sua democratização.

\section{CONCLUSÃo}

A principal novidade a registrar-se aqui é a percepção do Judiciário pela sociedade como serviço público essencial, que necessita de qualidade, economicidade, eficiência e disponibilidade, da mesma forma que a saúde, a educação e a segurança.

Os investimentos do governo em ações que efetivem o governo eletrônico, principalmente agora com o Plano Nacional da Banda Larga, irão aproximar o cidadão da questão da disponibilidade, via internet, dos serviços de saúde, educação, segurança e também de justiça.

As pesquisas sobre o desempenho e a efetividade do Judiciário ainda são poucas, mas elas tendem a se intensificar com a criação de observatórios da Justiça e da radiografia realizada pelo CNJ. Pesquisar o Judiciário, que se apresenta heterogêneo nas diferentes regiões do Brasil, inclusive quanto ao seu alcance social, torna-se importante no aperfeiçoamento da prestação de serviço judicial a partir da relação demanda/recursos orçamentários.

Conforme informação do CNJ, apenas o Judiciário brasileiro tem como objetivo disponibilizar em seus sites consulta sobre o andamento protocolar dos processos. A pesquisa sobre a qualidade da informação, sincronia com as bases de dados e a possibilidade não somente de consulta, mas de alguma interação com o sistema (do Processo Eletrônico) por parte do usuário/cidadão ainda precisa ser feita. Os estados do Brasil 
têm autonomia financeira e de gestão para o gerenciamento do seu Judiciário estadual. Dessa forma, mesmo sujeitos à mesma lei, cada sistema informatizado pode manter características e facilidades próprias. As novas versões do Processo Eletrônico devem incorporar as facilidades diferenciadas que cada sistema hoje utilizado tem de melhor.

Mesmo com a indicação de que o Processo Eletrônico venha a tornar o processo mais célere e mais acessível ao cidadão, é necessário identificar a qualidade dos serviços prestados e, principalmente, observar se a melhoria do acesso ao Judiciário, representará "mais justiça” para a sociedade.

Mesmo que o cidadão, lentamente se aproxime do Judiciário com a utilização dos sites da internet, principalmente para acessar e interagir com o Processo Eletrônico, pode-se inferir que os usuários que mais se beneficiam dessa interface com o Judiciário são os próprios operadores da justiça (juízes, promotores, cartorários, advogados). Estes, em razão de sua profissão, precisam acessar o sistema no seu dia a dia.

O cidadão, para conhecer melhor o sistema do judiciário e suas vantagens, acessando o Processo Eletrônico na internet, precisa passar pela inclusão digital em sistemas do judiciário.

No caso brasileiro, com o número do seu processo em mãos, o cidadão consegue fazer a consulta do trâmite transcorrido por seu processo, algo ainda não possível em outros países. Mas, provavelmente, terá dificuldade no entendimento daquilo que está descrito, pois o linguajar utilizado é o do judiciário, afastado do linguajar do cidadão comum. Então uma questão a ser equacionada é o entendimento do cidadão daquilo que contém o processo.

Por outro lado, vive-se um momento em que a melhoria da gestão do governo e, por consequência, a melhoria da gestão do Judiciário, passa pela ampliação dos recursos em hardware e software. Mas tal ampliação de nada servirá se o acesso ao cidadão for limitado por pontos de acesso escassos ou pela baixa velocidade. A expansão da banda larga neste momento é primordial, pois somente o uso massivo daquilo que já está disponível nos 
sites do Judiciário, passando pelo acesso ao Processo Eletrônico poderá balizar as necessidades de qualificação do "acesso".

O usuário/cidadão precisa opinar e interagir, somando-se ao esforço de técnicos que utilizem a engenharia e a gestão do conhecimento para qualificar de forma técnica e inteligente os sistemas informatizados e suas interfaces com o grande sistema que é o judiciário.

Da mesma forma, a integração da justiça com o cidadão em nossa sociedade passa pela atuação dos operadores da justiça, entre eles o juiz, que "gerencia" a unidade jurisdicional de $1^{\circ}$ grau. São os juízes os primeiros a atender as reivindicações da sociedade e a dar a esperança de um processo justo e célere. Compete então ao Judiciário ouvi-los, qualificá-los, equipá-los e valorizá-los, colocando-os como atores imprescindíveis no processo de democratização do Judiciário e com isto, da Justiça.

O Judiciário brasileiro aponta no sentido da melhoria contínua, capitaneada pelo CNJ, e principalmente pela adoção do Processo Eletrônico. O CNJ já está trabalhando na melhoria da gestão do Judiciário, fazendo uma radiografia do sistema, traçando metas e incentivando seu cumprimento, na busca de um Judiciário mais homogêneo. O próprio site do CNJ disponibiliza estas ações de melhoria de gestão e o conjunto de metas de 2009 e 2010. Além de propor e gerir o novo Judiciário, o conjunto de metas também tem se mostrado um instrumento de pesquisa contínua, cuja metodologia será aprimorada a cada nova edição.

As pesquisas utilizadas são muito importantes para a avaliação e a melhoria da interface da internet no Judiciário, e da própria Justiça. Mas elas precisam passar por uma qualificação dos seus indicadores e de uma integração dos seus objetivos, metodologia e resultados.

O real impacto da execução do conjunto de metas do CNJ, entre elas a aplicação do Processo Eletrônico, no modelo de "se fazer justiça" no Brasil, ainda precisa ser medido, não somente nas entranhas da estrutura do Judiciário, mas no tocante ao cidadão e à sociedade, os quais esperam por mais justiça e por mais democracia. 


\begin{abstract}
The Public Administration in Brazil is being rethought, so on its technological updating and on the renewal of their administration processes, as well on the democratic participation in its administration. The Conselho Nacional de Justiça (CNJ) is accomplishing a broad research of the judiciary system through the edition of a group of annual goals (2009 and 2010). One of the objectives is the effectiveness of the Electronic Process, through internet. The National Plan of Broadband will help the promotion of the electronic government, and the judiciary can take their services, in more qualified way, to the places that are today on the margin of the net. The real impact of the execution of the groups of goals of $\mathrm{CNJ}$ and the application of the Electronic Process still needs to be measured, not only into the structure of the judiciary, but concerning the citizen and to the society, which shout for more justice and democracy.
\end{abstract}

Keywords: Electronic Government. Management. Democracy. Justice.

\title{
REFERÊNCIAS
}

Barral, W. Desenvolvimento e sistema jurídico: a busca de um modelo teórico. In Barral, W.; Pimentel, L.O. (Org.). Teoria Jurídica e Desenvolvimento. Florianópolis: Fundação Boiteux, 2006, p. 11-35.

Bezerra, H.J.S.A: Educação para Formação de Juízes-Gestores: Um novo paradigma para um judiciário em crise. p. 1. 2010. Disponível em http:// www.cnj.jus.br/estrategia/wp-content/uploads/2010/03/Higyna-Formaçãode-Juízes-Gestores.pdf Acesso em 05/03/2010

Brasil. Constituição da República de 1988. http://www.planalto.gov.br/ ccivil_03/constituicao/constitui\%C3\%A7ao.htm

Dallari, D.A. O Poder dos Juízes. 3a Ed. São Paulo: Saraiva, 2008.

Garapon, A. O juiz e a democracia: o guardião de promessas. Trad. Maria Luiza de Carvalho. 2a Ed. Rio de Janeiro: Revan, 2001. p. 45 
Índice de Confiança no Judiciário da Fundação Getúlio Vargas. http://www.fgv.br/fgvportal/principal/idx_materia.asp?str_ chave $=14949 \&$ sessao $=2$

Metas Nacionais de Nivelamento de 2009 do Conselho Nacional de Justiça. Brasil. - http://www.cnj.jus.br/index.php?Itemid=963

Metas Prioritárias de 2010 do Conselho Nacional de Justiça. Brasil. www.cnj.jus.br/index.php?option=com_content $\&$ view $=$ article\& $i d=10350$ \&Itemid $=1125$

Nallini, J.R. A Rebelião da Toga. Campinas: Millenium, 2006. p. 163

Pimentel, L.O. Direito de propriedade intelectual e desenvolvimento. In: Barral, W. (Org.). Direito e desenvolvimento: um modelo de análise. São Paulo: Singular, 2005.

Plano Nacional de Banda Larga. Brasil. http://www.planalto.gov.br/ ccivil_03/_Ato2007-2010/2010/Decreto/D7175.htm

Programa estratégico do Tribunal de Justiça de Santa Catarina. http:// www.tj.sc.gov.br/institucional/assessorias/asplan/planejamento_ estrategico/index.html16. Silva, C.E.R..F. "Gestão Pública no Poder Judiciário", in Revista da ESMESC/Escola Superior da Magistratura do Estado de Santa Catarina - v.16, n. 22. Florianópolis: ESMESC, 2009, p. $35 / 51$

Rover, A.J. Introdução ao Governo Eletrônico. In: Rover, A. J. (org). Governo Eletrônico e a Inclusão Digital. Florianópolis: Ed. Boiteux, 2009. p. 22.

Ruschel, A.J. Análise do tempo dos Processos Penais de homicídio no Fórum de Justiça de Florianópolis julgados em 2004. Programa de Pós-Graduação em Antropologia Social da Universidade Federal de Santa Catarina. (Dissertação de Mestrado). Florianópolis, 2006. Disponível em http://www.cfh.ufsc.br/ levis/downloads/dissertacao/ATPPHFJFJ2004. pdf Acesso em 09/03/2010.

Ruschel, A.J.; Rover, A.J. Business Intelligence: Governo Eletrônico na Administração da Justiça. In: Galindo A., F.; Rover, A.J. (eds) Derecho,gobernanza y tecnologías de la información en la sociedad del conocimiento. Prensas Universitarias de Zaragoza. LEFIS Series 7, ISBN 978-84-92774-59-3 pp. 279-298. 2009. p.287. http://zaguan.unizar.es/ record/4489/files/ART-2010-002.pdf Acesso em 09/03/2010. 
44 AírTON JOSÉ RUSCHEL, CLÁUDIO EDUARDO REGIS DE FIGUEIREDO E SILVA, AIRES JOSÉ ROVER

Santos, B.S. A sociologia dos tribunais e a democratização da Justiça. In: Pela mão de Alice: o social e o político na pós-modernidade. 2. ed. São Paulo: Cortez, 1996.

Silva, C.E.R.F: Administração Gerencial e a Reforma Administrativa no Brasil. 1ª ed., 7a tiragem. Curitiba: Juruá, 2008.

Tribunal Superior do Trabalho. Brasil. http://www.tst.jus.br/

Vianna, L.W.; Burgos, M.: Revolução Processual do Direito e Democracia Progressiva, in Vianna, L.W. (Org.): A democracia e os três poderes no Brasil. Belo Horizonte: UFMG, 2002, p. 337/408. 